\title{
【usisersily
}

\section{Many-Objective Direct Policy Search in the Dez and Karoun Multireservoir System, Iranma}

Biglarbeigi, P., Giuliani, M., \& Castelletti, A. (2014). Many-Objective Direct Policy Search in the Dez and Karoun Multireservoir System, Iranma. https://doi.org/10.1061/9780784413548.105

Link to publication record in Ulster University Research Portal

Publication Status:

Published (in print/issue): 30/05/2014

\section{DOI:}

10.1061/9780784413548.105

\section{Document Version}

Author Accepted version

\section{General rights}

Copyright for the publications made accessible via Ulster University's Research Portal is retained by the author(s) and / or other copyright owners and it is a condition of accessing these publications that users recognise and abide by the legal requirements associated with these rights.

\section{Take down policy}

The Research Portal is Ulster University's institutional repository that provides access to Ulster's research outputs. Every effort has been made to ensure that content in the Research Portal does not infringe any person's rights, or applicable UK laws. If you discover content in the Research Portal that you believe breaches copyright or violates any law, please contact pure-support@ulster.ac.uk. 


\title{
Many-objective direct policy search in the Dez and Karoun multireservoir system, Iran
}

\author{
P. Biglarbeigi ${ }^{1,2}, \underline{\text { M. Giuliani }}^{1,2}$, A. Castelletti ${ }^{1,2}$ \\ ${ }^{1}$ Department of Electronics, Information, and Bioengineering, Politecnico di Milano, Milano, Italy \\ ${ }^{2}$ Hydroinformatics Lab, Como Campus, Politecnico di Milano, Milano, Italy \\ (pardis.biglarbeigi@mail.polimi.it; matteo.giuliani@polimi.it; andrea.castelletti@polimi.it)
}

\begin{abstract}
In this study we propose a novel approach to design Pareto-optimal operating policies via many-objective direct policy search in the Dez and Karoun multireservoir system (Iran), where the dimension of the system, the dry climate, and the presence of competing demands pose a number of challenges to water planners and managers. The three power plants connected to the main reservoirs in the modeled system (i.e., Dez, Karoun, and Masjed Soleyman) account for $20 \%$ of the national hydropower generation capacity. Irrigation and domestic supply, especially to the city of Ahwaz, are also strategic objectives, along with flood protection downstream of the dams. Given the complexity of the Dez and Karoun system and the multiple interests involved, the design of Pareto-optimal operating policies via many-objective direct policy search, combined with their a posteriori evaluation, represents an effective tool to support sustainable water reservoirs management in Iran. Our preliminary results show that the proposed decision analytic framework allowed the identification of the set of Pareto-optimal policies and discovered key tradeoffs to eventually aid the selection of few candidate compromise solutions that balance the competing objectives.
\end{abstract}

\section{INTRODUCTION}

In recent years, water resources around the globe have been subjected to increasing pressure due to continuous population growth, economic development, and climate change. In many developing countries, water plays a key role to complement carbonemitting energy production and support food security. Moreover, water resources decision-making problems are generally framed in heterogeneous socio-economic and ecologic contexts that involve multiple, conflicting and non-commensurable operating objectives. It is critical to adopt new management practices able to lead toward more efficient and sustainable uses of water resources.

In this study, we propose a novel approach to design Pareto-optimal operating policies in the Dez and Karoun multireservoir system (Iran). The system comprises three water reservoirs (i.e., Dez, Karoun, and Masjed Soleyman), which are mainly operated 
for hydropower production and account for $20 \%$ of the national hydropower generation capacity. Irrigation and domestic supply, especially to the city of Ahwaz (capital of the Khozestan province), are also strategic objectives. However, current system operation is producing frequent flood inundation downstream of the dams. In addition, seasonal low precipitations, high evaporation rates, and severe drought risks make the role of water reservoirs and their operating policies crucial in balancing the competing water demands in the system.

Studies on Iranian rivers are prevalently focused on a single specific issue, such as hydropower production (e.g., Karamouz et al., 2005; Dariane and Momtahen 2009), flooding (e.g., Heidari, 2009), or water quality (e.g., Dadolahi-Sohrab et al., 2012). However, these works lead to solutions that may appear effective with respect to a single point of view, but are actually unsatisfactory when evaluated from a larger, multiobjective perspective. Given the complexity of the Dez and Karoun system and the multiple interests involved, the design of Pareto-optimal operating policies via manyobjective direct policy search (Giuliani et al., 2013), combined with their a posteriori evaluation supported by visual analytics techniques (e.g., Woodruff et al., 2013), represents a potentially effective tool to support sustainable water reservoirs management in Iran. Direct policy search (DPS, see Rosenstein and Barto (2001)), also known as parameterization-simulation-optimization in the water resources literature (Koutsoyiannis and Economou, 2003), is a simulation-based approach which consists in the parameterization of the reservoir operating policies and the subsequent search, in the parameter space, of the optimal parameter vector with respect to the operating objectives of the problem. Following Nalbantis and Koutsoyiannis (1997), DPS can be seen as an optimization-based generalization for multi-objective problems of well known simulationbased, single-purpose heuristic operating rules (for a review, see Lund and Guzman (1999)).

The paper is organized as follows: the next section describes the Dez and Karoun system, while Section 3 presents the proposed methodology. Results are reported in Section 4 and final remarks, along with issues for further research, are presented in the last section.

\section{CASE STUDY DESCRIPTION}

Over $2 / 3$ of Iran suffer water shortages. Very low precipitation rates contribute to negative hydrologic balances in many river basins and groundwater aquifers, leading to rapid drops in overexploited water tables. As a consequence, there is an urgent need to find ways and means for solving the conflicting interests of urban, industrial, and agricultural sectors, especially given the limited availability of fresh water in most of the country.

\subsection{THE DEZ AND KAROUN RIVERS SYSTEM}

The Dez and Karoun rivers catchment (Figure 1) drains an area of $67,000 \mathrm{~km}^{2}$ and represents around $20 \%$ of the fresh water of the whole Iran. The three power plants 


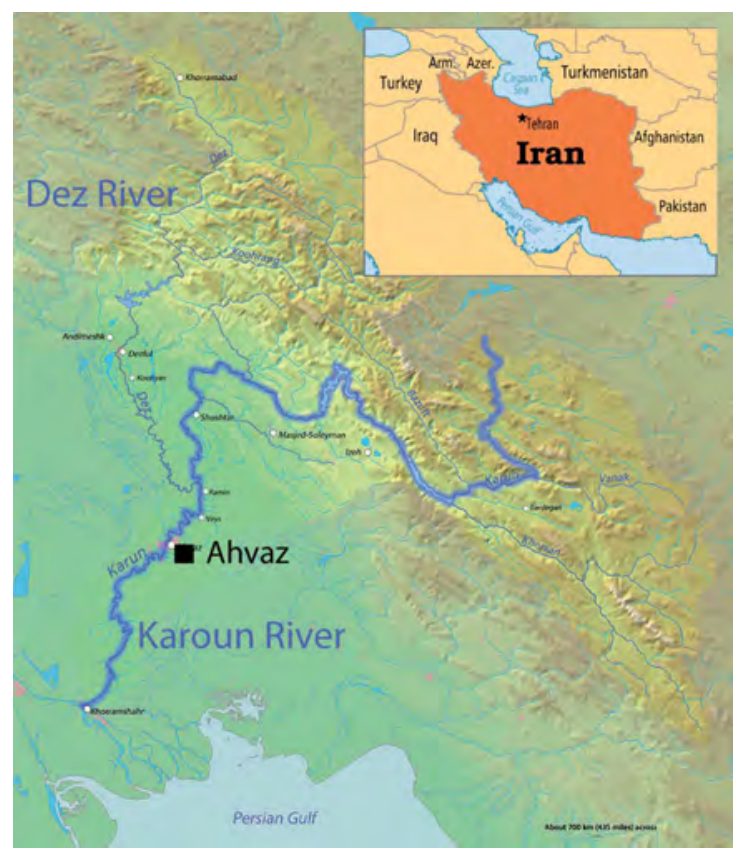

Figure 1: Map of the Dez and Karoun rivers system.

connected to the main reservoirs (i.e., Dez, Karoun, and Masjed Soleyman) account for $20 \%$ of the national hydropower generation capacity. Dez dam located on the Dez River has a storage capacity of $945 \mathrm{Mm}^{3}$ and the power generation capacity is $520 \mathrm{MW}$. Karoun and Masjed Soleyman dams, located on the Karoun River, have a capacity of 824 $\mathrm{Mm}^{3}$ and $261 \mathrm{Mm}^{3}$, respectively. The power generation capacity of both the power plants connected to Karoun and Masjed Soleyman dams is 2000 MW.

Irrigation and domestic supply are also strategic objectives in the system. The irrigated area extends for more than $250,000 \mathrm{hr}$. Besides irrigation, the other main consumer of water is the city of Ahwaz (1.5 million of citizens and capital of the Khozestan province) due to domestic as well as industrial water needs. Current system operation is however producing frequent flood inundation downstream of the dams due to the large volumes of water released for energy production. There are concerns about the project regarding the construction of additional hydropower plants in the upper catchments. In addition, seasonal low precipitations, high evaporation rates, and severe drought risks make the role of water reservoirs and their operating policies crucial in balancing the competing water demands in the system.

\subsection{MODEL FORMULATION}

The model of the system (Figure 2) is mainly based on the representation of the dynamics of the water reservoirs, defined by the mass balance equations of the water volume stored in each reservoir: 


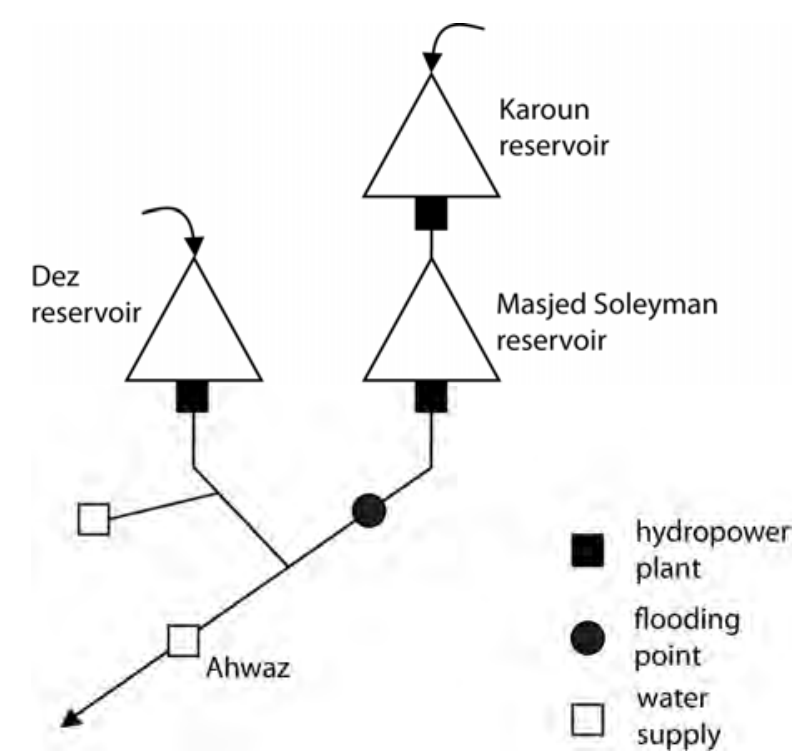

Figure 2: Schematic representation of the main model's component.

$$
\begin{aligned}
& s_{t+1}^{K}=s_{t}^{K}+n_{t+1}^{K}-r_{t+1}^{K}-E_{t}^{K} \\
& s_{t+1}^{M S}=s_{t}^{M S}+r_{t+1}^{K}-r_{t+1}^{M S}-E_{t}^{M S} \\
& s_{t+1}^{D}=s_{t}^{D}+n_{t+1}^{D}-r_{t+1}^{D}-E_{t}^{D}
\end{aligned}
$$

where $s_{t}{ }^{i}$ ( $i=$ Karoun, Dez, Masjed Soleyman) is the storage of the reservoirs, $n_{t+1}{ }^{i}$ the reservoir inflow, $E_{t}{ }^{i}$ the evaporation loss, $r_{t+1}{ }^{i}$ represents the volume released between $t$ and $t+1$, which is a function of storage, net inflow and release decisions $u_{t}{ }_{t}^{i}$. The time step of the model is 24 hours.

The main water uses, namely hydropower production, water supply to the city of Ahwaz and the agricultural districts downstream of Dez dam, and flood protection downstream of Masjed Soleyman dam, are formulated as follows:

- Hydropower: the maximization of the annual energy production in the system (to be maximized), defined as the sum of the productions of each power plant:

$$
J^{h y d}=\sum_{i=1}^{3}\left(1 / N_{y} \sum_{t=0}^{H-1} \eta g \gamma_{w} \Delta_{t+1} q_{t+1}^{T u r b} 10^{-6}\right.
$$

where $\mathrm{i}=($ Karoun, Dez, Masjed Soleyman $), \mathrm{N}_{\mathrm{y}}$ is the number of years, $\eta$ the turbine efficiencty, $\gamma_{w}=1000\left(\mathrm{~km} / \mathrm{m}^{3}\right)$ the water density, $\Delta_{t+1}(\mathrm{~m})$ the net hydraulic head (i.e., reservoir level minus tailwater level), $\mathrm{q}_{\mathrm{t}+1}$ Turb $\left(\mathrm{m}^{3} / \mathrm{s}\right)$ the turbined flow.

- Ahwaz supply: the minimization of the daily squared water deficit in Ahvaz, defined as the square difference of the water demand and water supplied to the city: 


$$
J^{A h v a z}=\frac{1}{H} \sum_{t=0}^{H-1} \max \left(\left(w_{t}^{A h v a z}-q_{t+1}^{A h v a z}\right), 0\right)^{2}
$$

where $\mathrm{w}_{\mathrm{t}}^{\text {Ahvaz }}$ is the water demand of Ahvaz at each time step and $\mathrm{q}_{\mathrm{t}+1}$ Ahvaz is the water supplied to the city and released by both Masjed Soleyman and Dez dams.

- Irrigation supply: the minimization of the daily squared water deficit of the irrigated areas downstream of Dez dam, defined as the square difference of the water demand and water supplied:

$$
J^{I r r}=\frac{1}{H} \sum_{t=0}^{H-1} \max \left(\left(w_{t}^{I r r}-q_{t+1}^{I r r}\right), 0\right)^{2}
$$

where $\mathrm{w}_{\mathrm{t}}^{\text {Irr }}$ is the water demand of the irrigated areas and $\mathrm{q}_{\mathrm{t}+1}$ Irr is the water supplied to these area and diverted from Dez dam releases.

- $\quad$ Flooding: the minimization of the maximum flooded area downstream of Masjed

Soleyman dam, defined according to the function introduced by Heidari (2009):

$$
J^{\text {Flood }}=\max _{t=0, \ldots, H-1}\left(\frac{r_{t+1}^{M S}}{0.2047}\right)^{1 / 0.9793}
$$

where $r_{t+1}$ MS is the released volume of water from Masjed Soleyman dam.

\section{MANY-OBJECTIVE DIRECT POLICY SEARCH}

The management of water reservoirs generally requires taking sequential decisions $\boldsymbol{u}_{\mathrm{t}}$ (e.g., the volume of water to be released) on the basis of the current system conditions described by the state vector $\mathbf{x}_{\mathbf{t}}$ (e.g., the water level in the reservoir). The optimal solution of a management problem is a feedback operating policy $\pi$, which, step-by-step, provides the vector of management decisions.

Direct policy search (DPS, see Rosenstein and Barto (2001)), also known as parameterization-simulation-optimization in the water resources literature (Koutsoyiannis and Economu, 2003), is a simulation-based approach where the operating policy $\pi$ is first parameterized within a given family of functions (e.g., linear or piece-wise linear) and then the parameters $\theta$ optimized with respect to the operating objectives of the management problem $\mathbf{J}\left(\pi_{\theta}\right)$. The combination of DPS with multi-objective evolutionary algorithms (MOEAs) allows the search of an approximation of the entire Pareto front, and the associated control policies, in a single optimization run. When the number of objectives is equal or larger than four units, the problem takes a many-objective nature, in contrast to traditional problems involving two or three objectives (Fleming et al., 2005). 
Technically, the management problem is formulated as:

$$
\pi_{\theta}^{*}=\arg \min _{\pi_{\theta}} J\left(\pi_{\theta}\right)
$$

where the policy $\pi_{\theta}$ is parameterized by parameters $\theta \in \Theta$ and $\mathbf{J}\left(\pi_{\theta}\right)$ is the vector of the operating objectives, computed by simulating the system under the parameterized policy $\pi_{\theta}$. The state of the system $\mathbf{x}_{\mathrm{t}}$ evolves according to the state-transition function $\mathbf{x}_{t+1}=f_{t}\left(\mathbf{x}_{t}, \mathbf{u}_{t}, \boldsymbol{\varepsilon}_{t+1}\right)$, where $\boldsymbol{\varepsilon}_{\mathrm{t}+1}$ is the vector of stochastic disturbances (e.g., inflows). Finding $\pi_{\theta}{ }^{*}$ is equivalent to find the corresponding optimal policy parameters $\theta^{*}$.

According to the DPS approach, the MOEA starts with a population of $\mathrm{N}$ individuals, representing $\mathrm{N}$ randomly generated parameter vectors $\theta$. The algorithm evaluates the fitness of each individual by simulating the system according to the operating policy $\pi_{\theta}$ and evaluating the objective vector $\mathbf{J}\left(\pi_{\theta}\right)$. Then, a new population is generated by selection, crossover and mutation with respect to the best individuals (i.e., the ones obtaining the highest values of fitness) according to the Pareto dominance criterion. This process is then repeated for a given number of iterations until a good approximation of the Pareto front is obtained.

However, DPS does not provide any theoretical guarantee on the optimality of the resulting operating policies, which are strongly dependent on the choice of the class of functions to which they belong and on the ability of the optimization algorithm to deal with non-linear models and objectives functions, complex and highly constrained decision spaces, and many conflicting objectives.

In this work, we use gaussian radial basis functions (RBFs) to parameterize the policies as they are capable of representing functions for a large class of problems $(\mathrm{Bu}-$ soniu et al., 2011). According to this parameterization, the $\mathrm{k}$-th release decision in the vector $\mathbf{u}_{\mathrm{t}}$ (with $\mathrm{k}=1, \ldots, \mathrm{K}$, where the number of release decisions $\mathrm{K}=3$ ) is defined as:

$$
u_{t}^{k}=\sum_{i=1}^{N} w_{i, k} \varphi_{i}\left(\chi_{t}\right)
$$

where $\mathrm{N}$ is the number of $\operatorname{RBFs} \varphi(\cdot)$ and $\mathrm{w}_{\mathrm{i}, \mathrm{k}}$ the weight of the $\mathrm{i}$-th $\mathrm{RBF}$. The weights are formulated such that they sum to one and are non-negative. The single RBF is defined as follows:

$$
\varphi_{i}\left(\chi_{t}\right)=\exp \left[-\sum_{j=1}^{M} \frac{\left(\left(\chi_{t}\right)_{j}-c_{j, i}\right)^{2}}{b_{j, i}^{2}}\right]
$$

where $\mathbf{M}$ is the number of input variables $\chi_{t}$ and $\mathbf{c}_{\mathrm{i}}, \mathbf{b}_{\mathrm{i}}$ are the $\mathrm{M}$-dimensional center and radius vectors of the $\mathrm{i}$-th $\mathrm{RBF}$, respectively. The total number of policy parameters is therefore equal to $\mathrm{N}(2 \mathrm{M}+\mathrm{K})$. 
Given the many-objective nature of the problem, we search the optimal operating policy parameters using the self-adaptive Borg MOEA (Hadka and Reed, 2013), which employs multiple search operators that are adaptively selected during the optimization based on their demonstrated probability of generating quality solutions. This algorithm has been shown to be highly robust across a diverse suite of challenging multi-objective problems, where it met or exceeded the performance of other state-of-the-art MOEAs (Hadka and Reed, 2012). The flexibility of the Borg MOEA to adapt to challenging, diverse problems makes it particularly useful for addressing DPS problems, where the shape of the operating policy and its parameter values are problem-specific and completely unknown a priori.

\subsection{EXPERIMENT SETTING}

The operating policy of the Dez and Karoun system is parameterized using 9 RBFs, accounting for 117 parameters. The release decisions are defined by the operating policy $\pi$ which depends on the following set of variables: $\sin (2 \pi t / 365), \cos (2 \pi t / 365), h_{t}{ }^{K}$,

$h_{t}{ }_{t}, h_{t}{ }^{D}$. Besides the water levels in the three reservoirs, representing the current water available, we include the time among the policy input to take into account the timedependency and cyclostationarity of the system and, consequently, of the operating policy.

The proposed many-objective DPS relies on the Borg MOEA, which has been shown to be relative insensitive to the choice of the algorithm parameters. We therefore use the default algorithm parameterization as suggested in (Hadka and Reed, 2013). Epsilon dominance is used to set the resolution of the operating objectives. In this work, we set epsilon values equal to 108 for Hydropower production, 80 for Flooding, 2000 for Irrigation, and 800 for Ahwaz. Each optimization was run for 10,000 function evaluations. To improve solution diversity and avoid dependence on randomness, we run 10 independent 10 optimization trials. The optimization was performed over inflows trajectories generated through the K-Nearest Neighbor resampling method proposed by Nowak et al (2010). This data-driven method captures observed statistics, is consistent with the lag-correlation structures in the observed data, and ensures summability and continuity across the daily time scale. The performance of the resulting policies is then computed over the validation horizon (2003-2006) with the historical inflows' trajectories. The final set of Pareto-optimal operating policies is defined as the set of nondominated solutions from the results of all the optimization trials.

\section{RESULTS}

Figure 3 reports the performance of the approximated Pareto-optimal operating policies evaluated over the validation horizon. The flooding and water supply to Ahwaz objectives are plotted on the primary axes, with the black arrows identifying the directions of increasing preference, with the bottom-left corner representing the ideal point with respect to the primary axes. The dimension of the circles is proportional to the Irri- 
gation deficit, with the best solutions represented by the smallest circles. Finally, the hydropower production is represented by the color of the circles, where the maximum production is red. So in the figure, the ideal solution of the 4-objective problem is a small and red circle close to the bottom-left corner of the figure.

The results reported in Figure 3 show clear tradeoffs between the four considered operating objectives. The solution that guarantees the highest hydropower production, represented by the large, red circle near the top-right corner of the figure, has a very poor performance in all the other three objectives. This suggests that a hydropowerdriven management of the system may produce negative impacts on the other waterrelated interests. The irrigation supply is also strongly conflicting with both hydropower and flooding, with most of the small circles placed on the right part of the figure and colored in blue. Finally, flood prevention requires reducing the performance in terms of hydropower and water supply to Ahwaz, while it is relatively independent to the irrigation supply. This is not surprising since floods are produced by Masjed Soleyman releases, while the irrigated areas withdraw water from the Dez River.

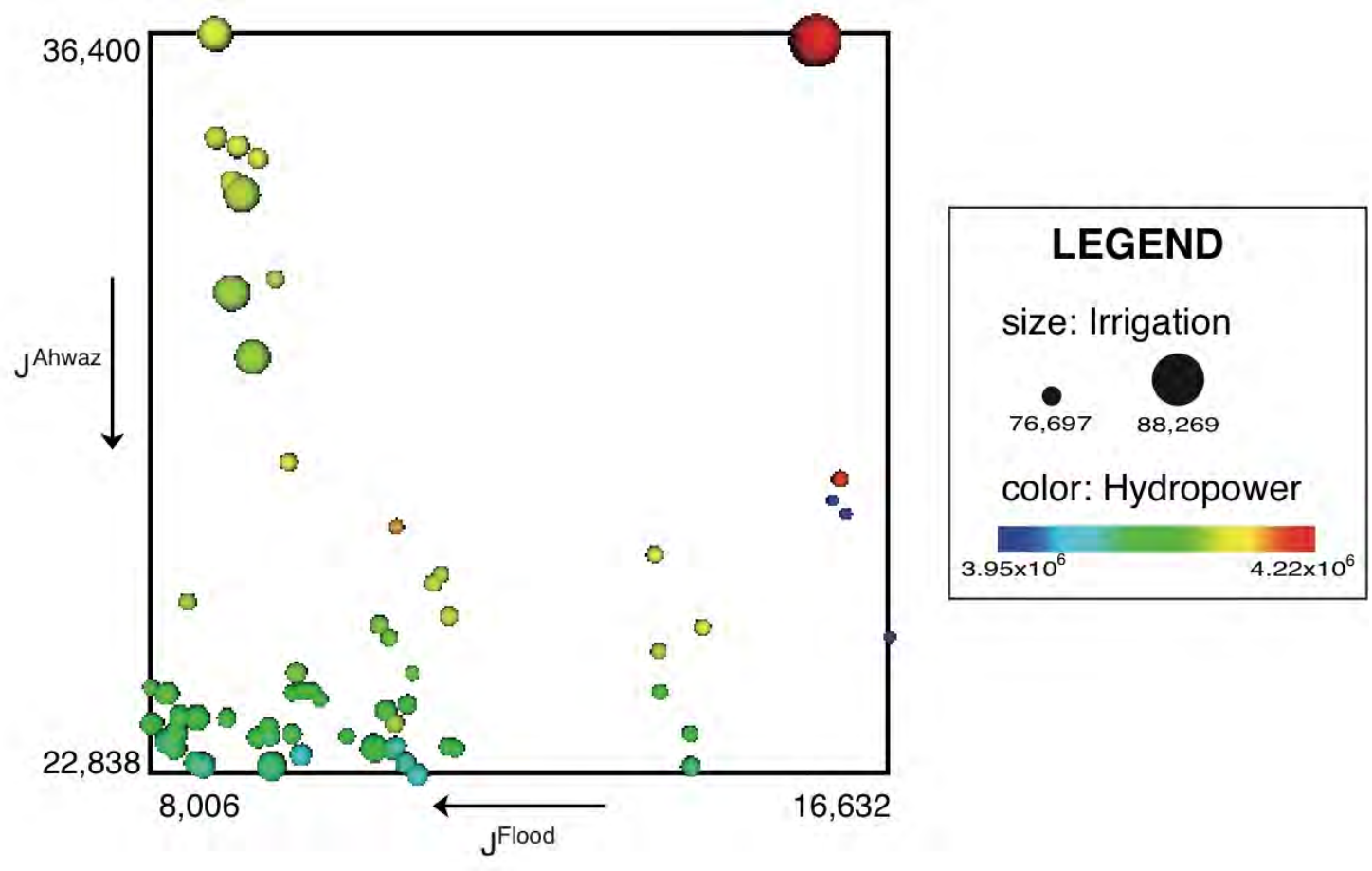

Figure 3: Performance of the Pareto-optimal operating policies over the validation horizon. 


\section{CONCLUSIONS}

The paper presents a novel approach for the design of Pareto-optimal operating policies in the Dez and Karoun multireservoir system (Iran). The proposed approach combines direct policy search, multi-objective evolutionary algorithms, and the a posteriori analysis of the objectives tradeoffs to eventually aid the selection of few candidate compromise solutions balancing the competing objectives. In particular, the combination of DPS with the Borg MOEA shows the potential to overcome the challenges related to the dimension of the modeled system and the many-objective nature of the problem. Results show that the four considered objectives are strongly conflicting. The regulation of the system has therefore to be carefully designed to balance all the interests involved. The a posteriori analysis of the Pareto-optimal solutions seems a promising approach, as it allows the identification of key tradeoffs to eventually aid the selection of few candidate compromise solutions that balance the competing objectives.

Future research efforts will focus on the comparison of the Pareto-optimal operating policies with the historical operation of the system to provide effective support to Iranian water managers. Furthermore, the introduction of non-stationary hydroclimatic conditions due to climate change impacts will allow the assessment of the long-term robustness of the identified operating policies.

\section{REFERENCES}

Busoniu, L., D. Ernst, B. De Schutter, and R. Babuska (2011). Cross-Entropy Optimization of Control Policies With Adaptive Basis Functions. IEEE Transactions on systems, man and cybernetics-Part B: cybernetics, 41(1), 196-209.

Dadolahi-Sohrab, A., F. Arjomand, and M. Fadaei-Nasab (2012), Water quality index as a simple indicator of watersheds pollution in southwestern part of Iran, Water and Environment Journal, 26, 445-454.

Dariane A. and S. Momtahen (2009). Optimization of Multireservoir Systems Operation Using Modified Direct Search Genetic Algorithm. Jurnal of Water Resources Planning and Management, 135(3), 141-148.

Fleming, P., R. Purshouse, and R. Lygoe (2005). Many-Objective optimization: an engineering design perspective. In: Proceedings of the Third international conference on Evolutionary Multi-Criterion Optimization. Guanajuato, Mexico.

Giuliani, M., J.D. Herman, A. Castelletti, and P.M. Reed (2013). Many-Objective Reservoir Policy Identification and Refinement to Reduce Institutional Myopia in Water Management. Water Resources Research. (under review). 
Hadka, D., and P. Reed (2012). Diagnostic assessment of search controls and failure modes in many-objective evolutionary optimization. Evolutionary Computation, 20(3), 423-452.

Hadka, D., and P. Reed (2013). Borg: An Auto-Adaptive Many-Objective Evolutionary Computing Framework. Evolutionary Computation, 21(2), 231-259.

Heidari, A. (2009). Structural master plan of flood mitigation measures. Natural Hazards and Earth System Sciences, 9, 61-75.

Karamouz, M., B. Zahraie, and S. Araghinejad (2005). Decision Support System for Monthly Operation of Hydropower Reservoirs: A Case Study. Journal of Computing in Civil Engineering, 19, 194-207.

Koutsoyiannis, D., and A. Economou (2003). Evaluation of the parameterization- simulation-optimization approach for the control of reservoir systems. Water Resources Research, 39(6), 1170-1187.

Lund, J., and J. Guzman (1999). Derived operating rules for reservoirs in series or in parallel. Journal of Water Resources Planning and Management, 125 (3), 143-153.

Nalbantis, I., and D. Koutsoyiannis (1997). A parametric rule for planning and management of multiple-reservoir systems. Water Resources Research, 33 (9), 2165-2177.

Nowak, K., J. Prairie, B. Rajagopalan, and U. Lall (2010). A nonparametric stochastic approach for multisite disaggregation of annual to daily streamflow. Water Resources Research, 46.

Rosenstein, M., and A. Barto (2001). Robot weightlifting by direct policy search. In International Joint Conference on Artificial Intelligence, vol. 17, pp. 839-846, Citeseer.

Woodruff, M., P. Reed, and T. Simpson (2013). Many objective visual analytics: rethinking the design of complex engineered systems. Structural and Multidisciplinary Optimization, 1-19. 